\title{
Political Science contra a democracia: a formação de uma tradição
}

\author{
ב \\ Álvaro Bianchi \\ Departamento de Ciência Política \\ Universidade Estadual de Campinas
}

\begin{abstract}
Resumo: O artigo analisa os anos de formação da Political Science nos Estados Unidos. A bibliografia tem destacado três características que constituíram o cerne de uma tradição estadunidense nesse campo de estudos: 1) o compromisso com os princípios do liberalismo, 2) o enfoque institucionalista e 3) a afirmação do caráter científico de seu empreendimento. De modo ainda pouco elaborado essas características estão presentes em uma "citizen literature" no final do século XVIII, mas é no processo de institucionalização da ciência política, na segunda metade do século XIX, elas são definidos de modo mais preciso tornando-se marcas distintivas dessa ciência nos Estados Unidos. A presente investigação apresenta como essas características se manifestaram no surgimento da Political Science e argumenta que para melhor compreendê-la é preciso destacar uma quarta característica: a desconfiança para com a democracia e o povo.
\end{abstract}

Palavras-chave: história da ciência política; institucionalismo; liberalismo; democracia

\begin{abstract}
The article analyzes the formation years of Political Science in the United States. The bibliography has highlighted three characteristics that would be the core of an American tradition in this study field: 1) the commitment to the principle of liberalism, 2) the institutionalist approach, and 3) the affirmation of the scientific character of its entrepreneurship. In a still little elaborated way, these haracteristics are present in a "citizen literature" in the end of the 18th century, but they were defined in a more precise way in the process of institutionalization of political science in the second half of the 19 th century, and has become the hallmarks of this science in the United States. This research shows how these characteristics have been displayed in the emergence of Political Science and argues that for its better understanding it is necessary to highlight a forth characteristic: its mistrust democracy and the people.
\end{abstract}

Keywords: history of political science; institutionalism; liberalism; democracy 
Já foi dito - e não foram poucos os que afirmaram isso - que a ciência política é uma ciência estadunidense. A influência exercida pelas universidades dos Estados Unidos, a difusão de suas revistas e a pujança de suas associações profissionais, são indicadores qualitativos que podem sustentar essa afirmação. Quantitativamente o número de cursos desse campo do conhecimento oferecidos em suas universidades, a quantidade de professores e pesquisadores dedicados ao estudo da política e o número de alunos matriculados em cursos de ciência política fornecem dados impressionantes ${ }^{1}$.

Para afirmar que a ciência política é uma ciência estadunidense não bastam esses indicadores. Eles permitem avaliar o grau de desenvolvimento e institucionalização da ciência política nos Estados Unidos e, até mesmo, de sua hegemonia internacional. Mas para afirmar que uma ciência assume um perfil "nacional" específico, ou seja, que ela se encontra fortemente marcada pela história de um determinado país seria preciso ir além desses indicadores e revelar as características distintivas que permitiriam atribuir a essa ciência esse perfil "nacional".

Os autores que procuraram reconstruir a história da ciência política nos Estados Unidos destacaram que quando esta ciência deu seus primeiros passos rumo à institucionalização, no final do século XIX, ela já o fez com base em uma tradição nacional que tinha como características principais: 1) o compromisso com os princípios do liberalismo, 2) o enfoque institucionalista e 3) a afirmação do caráter científico de seu empreendimento. Essas características se inscreveriam no próprio processo de constituição da nova República como nação. O que os primeiros passos dessa nova tradição permitem demonstrar é a existência de uma quarta característica: uma profunda desconfiança para com a democracia e o povo.

\section{Da citizen literature à science of politics}

A ideia de uma ciência da política começa a dar suas primeiras braçadas neste lado do Atlântico juntamente com a luta pela independência dos Estados Unidos e a construção de uma nova nação. Escrevendo no inverno de 1776 a respeito da emancipação das colônias inglesas, John Adams, que viria a ser o segundo presidente desse país, traçou as linhas gerais daquilo que viria a ser uma ciência estadunidense da política:

\footnotetext{
${ }^{1}$ Sobre a ideia de uma ciência política estadunidense ver, p. ex. Crick (1960, p. vi): "a ideia de uma ciência da política tornou-se em nossa era distintivamente estadunidense". Em 2006, 39.409 estudantes obtiveram o título de bacharel em ciência política, 2.054 o de mestre e 649 o de doutor (NCES, 2007).
} 
"If I was equal to the task of forming a plan for the government of a colony, I should be flattered with your request, and very happy to comply with it; because, as the divine science of politics is the science of social happiness, and the blessings of society depend entirely on the constitutions of government, which are generally institutions that last for many generations, there can be no employment more agreeable to a benevolent mind than a research after the best" (ADAMS, 1851, v. IV, p. 193. Grifos meus).

Se a política deveria ter como finalidade a felicidade social, a "divina ciência da política" deveria ser uma "ciência da felicidade social" e como tal deveria proteger a liberdade dos indivíduos e, consequentemente, sua propriedade. Para atingir essa felicidade era necessária uma constituição apropriada do governo, a qual assentaria as bases para a construção de instituições capazes de garantir esse objetivo de modo durável. A ciência da política era assim apresentada de modo preciso mediante a definição de seu objeto - as instituições políticas - e de seu objetivo - a proteção da liberdade individual e da propriedade privada.

Os Artigos da Confederação proclamados em 1776 não resolveram definitivamente os problemas decorrentes da constituição de uma nova nação. 0 caráter descentralizado da nova República dificultou, por exemplo, a criação de um exército unitário, ou mesmo a emissão de papel moeda. Para muitos essa era uma base política extremamente frágil para um novo Estado. Escrevendo em 1782, quando essa fragilidade já Ihe parecia evidente, Thomas Jefferson registrou: "This constitution was formed when we were new and unexperienced in the science of government. It was the first, too, which was formed in the whole United States. No wonder then that time and trial have discovered very capital defects in it." (JEFFERSON, 1904 v. IV, p. 17. Grifos meus). No entanto, esses defeitos, como apontava a seguir Jefferson já eram conhecidos. Benjamin Rush, um dos signatários da Declaração da Independência, afirmava, em 1787, que seus concidadãos entendiam perfeitamente os princípios da liberdade, mas eram "ignorant of the forms and combinations of power in republics" (RUSH, 1947, p. 26). As ameaças de revoltas internas preocupavam vários dos líderes políticos mais destacados da nova nação e Rush considerava que a deficiência do poder coercitivo da Confederação era seu primeiro defeito (idem, p. 27).

A "ciência do governo" mencionada por Jefferson não se distanciava daquela "ciência da política" à qual se referia Adams. Seus objetivos e seu objeto eram idênticos. Por outro lado, em vários aspectos essa ciência da política distinguia-se da filosofia política sobre a qual pretendia assentar-se. Aristóteles, Cícero, John Locke e Algernon Sidney eram autores sempre citados, mas ao lado deles Jefferson 
colocava os "harmonizantes sentimentos daqueles tempos, seja expressos em conversações, cartas, ensaios impressos" (1905, v. 10, p. 409). O tipo de reflexão conduzida no Novo Mundo distinguia-se daquela levada a efeito pelos clássicos. 0 objetivo desta última era mais imediato, mais concreto e, certamente, mais pragmático: construir no presente as instituições políticas que permitissem garantir uma ordem política estável que assegurasse as riquezas e propriedades existentes, ou, como dizia Adams, assegurar a paz e a felicidade.

Para os novos cientistas da política, não se tratava, portanto, de encontrar os princípios abstratos que permitiriam garantir essa paz e a felicidade e sim de arquitetar as formas políticas que efetivamente poderiam trazer esses resultados. A literatura que produziram não era composta de tratados, compêndios ou manuais e sim de panfletos, cartas, discursos, relatórios, leis e textos constitucionais. Jefferson era consciente da diferença existente entre essa literatura e os clássicos do pensamento político, dentre eles John Locke. Ele considerava "Locke's little book on government" perfeito, mas quando se tratava dos aspectos práticos do artesanato político sua recomendação era outra: "Descending from theory to practice there is no better book than the Federalist." (JEFFERSON, 1905, v. VI, p. 63).

O escritor Bliss Perry chamou esses textos políticos de "citizen literature" e considerou esta "the most satisfactory expression of the thought and feeling of that generation" (PERRY, 1918, p. 72). O estilo sóbrio e em certos momentos ascético desses escritos não ocultava a erudição. Mas esta era firmemente contida pelo pragmático espírito do capitalismo que detestava todo desperdício de energias e dirigia seus esforços para a solução de problemas concretos da vida civil. Juntamente com as instituições da monarquia, também o estilo rebuscado da prosa inglesa contemporânea deveria ser rejeitado na nova República e considerado nãonatural. "The present is the age of simplicity in writing in America", sentenciava Benjamin Rush em 1788 (1942, p. 102).

Quando para resolver problemas concretos uma nova Constituição foi posta em discussão, na segunda metade da década de 1870, a "ciência da política" foi novamente convocada. Seus contornos, nesta ocasião, se tornaram mais nítidos e um programa de pesquisa mais detalhado tomou corpo. Se em Adams ou Jefferson a ciência da política ou do governo se apresentava ainda como um dever ser, nos escritos de Alexander Hamilton e James Madison ela já era um programa de pesquisa. Escrevendo sob o pseudônimo de Publius um artigo que viria a se tornar decisivo no argumento dos defensores da nova Constituição, Hamilton definiu os contornos de uma ciência da política que dava seus primeiros passos: 
"The science of politics, however, like most other sciences, has received great improvement. The efficacy of various principles is now well understood, which were either not known at all, or imperfectly known to the ancients. The regular distribution of power into distinct departments; the introduction of legislative balances and checks; the institution of courts composed of judges, holding their offices during good behaviour; the representation of the people in the legislature, by deputies of their own election; these are either wholly new discoveries, or have made their principal progress towards perfection in modern times" (MADISON et al., 2001, p. 38).

O vocabulário não era evidentemente consensual. Hamilton, como visto nessa passagem, preferia escrever a respeito de uma "ciência da política". Madison não usou em suas obras uma única vez essa expressão e optou por "ciência política" ou "ciência do governo" (1900, v. VIII, p. 304; v. IX, p. 181, 430, 546, 549 e 610). Thomas Jefferson, por sua vez, referia-se em seus escritos à "ciência do governo", assim como James Wilson e George Washington (JEFFERSON, 1904, v. IV, p. 17, 1905. v. VI p. 63; e v. XII, p. 154; WILSON, 2007, v. 1, p. 217 e 712 e WASHINGTON, 1987, p. 509).

As dissonâncias lexicais não encobrem, entretanto, as fortes semelhanças. 0 pensamento de John Locke era uma unanimidade (cf. CRICK, 1960, p. 8-15). Nos debates constitucionais, entretanto, era principalmente a Montesquieu que todos se referiam - seja para recusar sua ideia de que uma República era inviável em um país de grandes dimensões, seja para defender a separação de poderes ${ }^{2}$. Justiça seja feita, Hamilton e Madison tornaram as ideias do barão mais concretas, atribuindo-Ihes contornos institucionais mais precisos. Se para Montesquieu a constituição da Inglaterra era não apenas um modelo como também um ponto de chegada, para Hamilton e Madison ela era, principalmente, um ponto de partida que deveria inspirar novas instituições políticas.

Quem ler com atenção o famoso artigo Federalista $n^{\circ} 10$, redigido por James Madison e no qual os argumentos de Hamilton foram desenvolvidos poderá verificar "valuable improvements" feitos pelos líderes da nova nação "on the popular models, both ancient and modern" (MADISON et al., 2001, p. 42). Nesse notável texto,

\footnotetext{
2 Segundo Jefferson, "study of the law is useful in a variety of points of view. It qualifies a man to be useful to himself, to his neighbors, \& to the public. It is the most certain stepping stone to preferment in the political line. In political economy I think Smith's wealth of nations the best book extant, in the science of government Montesquieu's spirit of laws is generally recommended. It contains indeed a great number of political truths; but also an equal number of heresies: so that the reader must be constantly on his guard" (JEFFERSON, 1905, v. VI, p. 63).
} 
Madison afirmou que a "instability, injustice, and confusion" presentes nos conselhos públicos são os principais problemas enfrentados pelos governos populares. Na raiz desses problemas encontram-se as facções, daí que o principal objetivo de uma ordem bem constituída deva ser "to break and control the violence of faction" (idem).

O tratamento dado por Madison a esta questão era fortemente realista e não escondia as razões desses problemas. Para este autor, a principal causa do nascimento das facções "has been the various and unequal distribution of property" (idem, p. 44) decorrente da desigual distribuição das faculdades naturais dos homens. A desigualdade de propriedades teria, assim, suas causas naturais, e as facções que sobre essa desigualdade se constituiriam não poderiam ser suprimidas sem suprimir as causas, o que seria impossível a menos que se suprimisse a propriedade. Obviamente não era o que Madison desejava, por isso, ao invés de suprimir as causas das facções investigou os meios institucionais que permitiriam neutralizar ou minimizar seus efeitos.

O aristocrático temor de Madison e dos demais federalistas residia na possibilidade de uma maioria de não proprietários impor sua vontade sobre uma maioria de proprietários. A união da maioria em uma única facção organizada a partir de interesses comuns deveria ser evitada. A revolta liderada por Daniel Shays contra as execuções por dívida em Massachusetts entre 1786 e 1787 estava ainda presente na memória de todos e principalmente daqueles que defendiam a nova Constituição. Com muito custo a rebelião foi debelada e seus protagonistas presos e condenados à morte. Hamilton se referiu à rebelião no Federalista $n^{0} 21$ alertando para os riscos de uma facção ser bem sucedida: "A successful faction may erect a tyranny on the ruins of order and law, while no succour could constitutionally be afforded by the union to the friends and supporters of the government. The tempestuous situation from which Massachusetts has scarcely emerged, evinces, that dangers of this kind are not merely speculative." (MADISON et al., 2001, p. 100). E Madison, mais adiante, retornou ao problema de uma facção da maioria, alertando no Federalista $n^{\circ} 51$ : "It is of great importance in a republic not only to guard the society against the oppression of its rulers but to guard one part of the society against the injustice of the other part. If a majority be united by a common interest, the rights of the minority will be insecure" (Idem, p. 270).

Foi essa mesma desconfiança com a democracia e o povo que levou James Madison a definir a nova nação como uma república e a rejeitar explicitamente a ideia de que a nova Constituição assentasse as bases para uma democracia. 0 argumento do futuro presidente dos Estados Unidos começava de modo bastante convencional: as democracias puras eram governos realizáveis apenas em uma sociedade com um pequeno número de cidadãos e, mesmo assim, nunca foram capazes de conter as turbulências e, pior, "have ever been found incompatible with 
personal security, or the rights of property; and have, in general, been as short in their lives, as they have been violent in their deaths" (MADISON et al., 2001, p. 46).

O remédio receitado por Madison para os males apresentados pela Confederação não eram, portanto, remédios democráticos. A república preconizada pelos federalistas deveria se distinguir de modo claro dos governos nos quais o povo exercesse diretamente o poder soberano. Segundo o futuro presidente, tais diferenças seriam "first, the delegation of the government, in the latter, to a small number of citizens elected by the rest; secondly, the greater number of citizens, and greater sphere of country, over which the latter may be extended" (MADISON et. al., 2001, p. 46). Tais diferenças permitiriam manter sob controle as facções e evitar que a liberdade e a propriedade asseguradas pela Constituição fossem ameaçadas ${ }^{3}$.

Encontrar os meios institucionais que permitissem neutralizar ou minimizar os perigos da democracia e o ímpeto e as paixões populares era o programa de James Madison, Alexander Hamilton e tantos outros. A esse respeito Hamilton parece ter ido mais longe do que seus companheiros, propondo na Convenção Federal um presidente e um senado vitalícios, como meios institucionais de conter os arroubos populares:

"All communities divide themselves into the few and the many. The first are the rich and well-born, the other the mass of the people. The voice of the people has been said to be the voice of God; and, however generally this maxim has been quoted and believed, it is not true in fact. The people are turbulent and changing; they seldom judge or determine right. Give, therefore, to the first class a distinct, permanent share in the government. They will check the unsteadiness of the second, and, as they cannot receive any advantage by a change, they therefore will ever maintain good government. Can a democratic Assembly, who annually revolve in the mass of the people, be supposed steadily to pursue the public good? Nothing but a permanent body can check the imprudence of democracy" (HAMILTON, 1904, v. 1, p. 401).

Dando seus primeiros passos nos Estados Unidos a ciência política debruçava-se sobre as instituições existentes ou preconizada pelos filósofos para dar-Ihes conteúdos novos e formas mais consistentes, capazes de garantir a ordem e a estabilidade necessárias para a prosperidade. Foi nas antigas colônias inglesas

\footnotetext{
3 Segundo Madison, "a rage for paper money, for an abolition of debts, for an equal division of property, or for any other improper or wicked project, will be less apt to pervade the whole body of the union, than a particular member of it" (MADISON et al., 2001, p. 48).
} 
que a teoria da separação dos poderes assumiu sua forma concreta mais desenvolvida. Madison deixou isso claro em uma carta de 1800, na qual escreveu:

"It has become an axiom in the science of government, that a separation of the legislative, executive, and judicial departments is necessary to the preservation of public liberty. Nowhere has this axiom been better understood in theory, or more carefully pursued in practice, than in the United States" (MADISON, 1900, v. 6, p. 371).

E em uma carta a Andrew Stebensons, redigida em 1830, registrou aquelas que considerava as principais conquistas do modelo político estadunidense e os avanços que ele representava para a "ciência do governo":

\begin{abstract}
"Here the established system aspires to such a division and organization of power as will provide at once for its harmonious exercise on the true principles of liberty over the parts and over the whole, notwithstanding the great extent of the whole; the system forming an innovation and an epoch in the science of Government no less honorable to the people to whom it owed its birth, than auspicious to the political welfare of all others who may imitate or adopt it" (MADISON, 1900, v. 10, p. 430).
\end{abstract}

Opinião semelhante foi apresentada de modo ainda mais enfático e até mesmo profético por James Wilson, um dos signatários da Declaração de Independência e, posteriormente, membro da Suprema Corte dos Estados Unidos. Dirigindo-se à Convenção da Pennsylvania que deveria ratificar a Constituição, em 1878, Wilson afirmou que os desenvolvimentos feitos nesse país na "ciência do governo" fariam que em todo o mundo seus textos fundamentais fossem lidos e estudados "and hence it is not improbable that she will take the lead in political knowledge" (WILSON, 2007, v.1, p. 282).

Professor de direito no College of Philadelphia e, depois, na University of Pennsylvania a partir de 1791, Wilson pretendia escrever um tratado de direito capaz de rivalizar com os comentários de William Blackstone às leis da Inglaterra. Essa tentativa diferenciava-se claramente pela sua profundidade e seu caráter daquela "citizen literature" que marcava a época. Não conseguiu, entretanto, finalizar sua obra, mas deixou suas Lectures on Law, nas quais suas ideias eram apresentadas de modo mais sistemático, ao contrário da maioria de seus contemporâneos. Mas se os objetivos e mesmo o estilo da obra de Wilson diferiu de seus contemporâneos, seu juízo a respeito da nova "ciência do governo" era 
comum. Em suas Lectures, deixou claro o caráter prático, mais do que teórico, da contribuição dos Estados Unidos à ciência política. Segundo Wilson, a formação e estabelecimento de constituições eram "an immense practical improvement, introduced by the Americans into the science of government and jurisprudence" (WILSON, 2007, v.1, p. 712).

Esse "imenso desenvolvimento prático" deveria difundir-se por meio das instituições da nova nação. Para adquirir a estabilidade desejada ele precisaria de um povo acostumado a viver de acordo com os valores e princípios republicanos. Tornava-se necessário, para tal, educar esse povo. Daí que a ciência da política ou do governo fosse, também, um projeto pedagógico. Essa preocupação pedagógica pode ser encontrada na obra de Benjamin Rush, um dos signatários da Declaração da Independência. Escrevendo em 1787, Rush considerava que a Revolução Americana não poderia ser confundida com a Guerra Americana. Esta última já havia terminado, mas a Revolução ainda estava em curso, uma vez que ainda era necessário estabelecer não apenas uma nova forma de governo, como também preparar os princípios, a moral e os modos dos cidadãos para essas formas de governo (RUSH, 1947, p. 26).

Para adequar os princípios e o modo de vida dos cidadãos à nova forma de governo republicana era necessária, para Rush, uma sociedade de conhecimento (idem, p. 97). A criação de uma universidade federal como parte de um abrangente sistema de ensino permitira a constituição dessa sociedade. Segundo esse autor: "In this university, let every thing connected with government, such as history the law of nature and nations the civil law the municipal laws of our country and the principles of commerce, be taught by competent professors" (RUSH, 1947, p. 29).

Segundo Castel (1964, p. 280), essa foi a primeira vez que a ideia de uma universidade nacional foi apresentada publicamente ${ }^{4}$. Em seu Plan of a Federal University, de 1788, Rush propôs uma "federal university" a qual deveria ensinar exclusivamente aqueles temas que permitiriam preparar a juventude para a vida civil e pública. A lista de temas que deveriam ser aprendidos nessa instituição não era extensa e todos eles estavam diretamente justificados com base em sua utilidade prática para os negócios e a política. O primeiro desses temas propostos pelo autor era:

\footnotetext{
${ }^{4}$ Esse discurso é de 1787, mas já em 1786, Rush propunha "Let there be one university in the state, and let this be established in the capital. Let law, physic, divinity, the law of nature and nations, economy, be taught in it by public lectures in the winter season, after the manner of the European universities, and let the professors receive such salaries from the state as will enable them to deliver their lectures at a moderate price" (1947, p. 98. Grifos meus).
} 
"The principles and forms of government, applied in a particular manner to the explanation of every part of the Constitution and laws of the United States, together with the laws of nature and nations, which last should include every thing that relates to peace, war, treaties, ambassadors, and the like" (RUSH, 1947, p. 101).

A proposta de Rush encontrou adeptos entre seus contemporâneos. Jefferson, já havia tentado transformar o William and Mary College na Universidade de Virginia, mas encontrou forte resistência da Igreja anglicana, à qual o College estava vinculado. Engajou-se nesse novo projeto de uma federal university ao mesmo tempo em que não deixava de acalentar a proposta de constituição de uma universidade na Virginia. Esse engajamento era entendido como uma luta pela difusão dos ideais republicanos. George Washington também defendeu este novo projeto e em seu pronunciamento anual de 1796 explicitou seu compromisso com a idéia de uma instituição nacional de ensino superior cujo objetivo deveria ser a difusão de princípios, opiniões e modos republicanos no corpo de cidadãos ${ }^{5}$. Para tal difusão, o lugar de uma "ciência do governo" era fundamental: "The more homogeneous our citizens can be made in these particulars, the greater will be our prospect of permanent union; and a primary object of such a national institution should be, the education of our youth in the science of government" (WASHINGTON, 1988, p. 509).

Mas o projeto de Jefferson em Virginia tardou a se concretizar e o sonho de Washington naufragou, muito embora tivesse prescrito em seu testamento a disposição de terras e recursos financeiros para a fundação e manutenção de uma universidade (WASHINGTON, 1988, p. 607 e 670-671). Surpreendentemente, apesar do engajamento de importantes lideres da nova República o projeto de uma ciência da política ou do governo demorou para adquirir contornos institucionais mais precisos.

\section{Da ética política à ciência política}

Na primeira metade do século XIX disciplinas de política podiam ser encontradas em cursos de Direito, História e Economia. Mas apenas em 1858 foi criada a primeira cadeira de Ciência Política e História na Columbia University e atribuída ao alemão Francis Lieber. A nomeação de Lieber para esse posto ilustra os novos desenvolvimentos da ciência política nos Estados Unidos. Refugiado

\footnotetext{
${ }^{5}$ Para a defesa por parte de Washington de uma universidade nacional, ver Adams (1888, p. 25 ss.).
} 
alemão comprometido com as ideias do liberalismo, Lieber iniciou seus estudos no campo da Ética com a publicação de seu Manual of Political Ethics (1838). O subtítulo dessa obra - "designed chefly for the use of Colleges and students of Law" - revelava qual era o público que seu autor pretendia atingir. Esse empreendimento intelectual era agora estritamente acadêmico e se dirigia primeiramente a uma audiência de universitários e não mais à opinião publica como muitas das obras precedentes.

O livro de Lieber encontrava-se muito distante do projeto intelectual de Jefferson e seus contemporâneos e muito próximo dos tradicionais modos de refletir sobre a política na Europa e principalmente da filosofia política kantiana. É possível dizer que com Lieber pela primeira vez a ciência política praticada nos Estados Unidos se afastava das exigências postas pelos problemas da política presente (BRYSON, 1932, p. 319). O discurso do Manual of Political Ethics era construído em elevados níveis de abstração e nos livros I e III, nos quais os princípios da ética e da ética política eram apresentados, assumia os contornos precisos de um discurso filosófico.

Mas Lieber estava sob uma dupla influência. Por um lado ele expressava os influxos teóricos da Staatswissenschaft alemã, o que fica claro, principalmente no livro II do Manual of Political Ethics, o qual começava por explicar o que era a lei, a propriedade e a civilização para depois definir o Estado como uma sociedade "founded on the relations of right" (LIEBER, 1876, v. 1, p. 152) ${ }^{6}$. Por outro lado, o mesmo Manual abordava temas que dificilmente poderiam ser compreendidos sob o título genérico de ética política, tais como sistemas eleitorais (voto), partidos e organização da representação política (ver 1876, v. 2, livros V.VII). Era a respeito destes últimos temas que o professor alemão demonstrava um pensamento mais estadunidense que germânico, tratando de modo mais concreto as instituições políticas de sua época 7 .

Não foi esta, entretanto, a obra que fez a fama de Lieber nos Estados Unidos e sim On Civil Liberty and Self-Government, publicada em 1853 quando seu autor ainda era professor na University of South Carolina. Nela o liberalismo de Lieber ainda mantinha seu conteúdo nacionalista herdado do pensamento político alemão,

\footnotetext{
${ }^{6}$ Segundo Lieber: "The relation which thus exists between these rational beings, this demand of what is just made by each upon each, is the relation of right; and the society founded upon this basis, which exists because right (jus) in its primordial sense exists and ought to exist between men, which has to uphold and insist upon it, which has to enforce it, since every man has a right to be a man, that is, a free acting or rational being, because he is a man - this society is the state" (1876, v.1, p. 150).

7 Entretanto, mesmo nesses capítulos Lieber adota uma perspectiva histórica comparativa, o que também o diferenciava do modo de abordar esses temas predominante no período anterior nos Estados Unidos. Segundo Bryson, mesmo quando abordava temas candentes da política, como a escravidão ou as tarifas elevadas, Lieber abordava esses temas eticamente (BRYSON, 1932, p. 319). Sobre o Manual ver tb. Gunnell (1993, p. 28-29).
} 
mas sua ênfase na liberdade civil e no autogoverno o vinculavam de modo mais intenso ao liberalismo propriamente anglo-saxão. O que mais interessa aqui é sua reelaboração do conceito de Estado, de modo a destacar sua dimensão institucional. Segundo Lieber,

\footnotetext{
"The state is a society, or union of men - a sovereign society and a society of human beings, with an indelible character of individuality. The state is, moreover, an institution which acts through government, a contrivance which holds the power of the whole, opposite to the individual. (...) The term state, at the same time, means a society of men, that is, of beings with individual destinies and responsibilities from which arise individual rights" (1874, p. 38-39. Grifos meus).
}

Essa reelaboração implicou no extenso tratamento dado pelo autor às "instituições da liberdade" definidas de modo a destacar seu caráter formal e legal. Esse legalismo, ou seja, essa preocupação com a norma e o papel central da lei na atividade governamental constituiria a "primeira característica determinante que surge do velho institucionalismo" (PETERS, 2003, p. 20). O legalismo no estudo das instituições políticas, como é sabido, teve largo curso na ciência política estadunidense e apesar de ter sido colocado em questão já no começo do século XX foi apenas a partir da década de 1970, com o neoinstitucionalismo contemporâneo, que ele foi definitivamente superado em favor de definições menos formais ou jurídicas. Segundo o futuro professor de Columbia,

\footnotetext{
"an institution is a system or body of usages, laws, or regulations of extensive and recurring operation, containing within itself an organism by which it effects its own independent action, continuance, and generally its own farther development. Its object is to generate, effect, regulate, or sanction a succession of acts, transactions, or productions of a peculiar kind or class. The idea of an institution implies a degree of self-government. Laws act through human agents, and these are, in the case of institutions, their officers or members" (Idem, p. 300).
}

Foi a partir dessa perspectiva que Lieber anunciou em seu discurso de posse na cadeira de História e Ciência Política na Columbia University que "There is no other civil liberty than institutional liberty" (1859, p. 78). No mesmo sentido, havia definido anteriormente essa "institutional liberty", como decorrente do "institutional self-government", ou seja, o governo popular, o qual era formado por um grande organismo de instituições ou um conjunto de sistemas legais harmônicos. A adoção 
de uma forma institucional apropriada permitiria compatibilizar a liberdade dos indivíduos e a necessidade de adotarem um governo para proteger essa liberdade. Seguindo a tradição dos Federalistas, o professor de Columbia distinguia esse autogoverno de um governo desarticulado da maioria (LIEBER, 1874, p. 319). Mas o aristocrático temor que os Federalistas tinham de uma facção majoritária recebia na obra de Lieber seu nome atual: tratava-se do temor ao absolutismo democrático de inspiração rousseauniana ou, mais exatamente, do medo do comunismo cujo espectro havia descoberto a América (1859, p. 78 e 112ss, 1860, p. 29). Cabia ao "institutional self-government" debelar esse espectro.

Ao contrário de sua obra anterior, On Civil Liberty and Self-Government aproximou-se pelos temas abordados, pelo tratamento dado a eles e também pelo seu estilo, muito mais daquela "ciência da política" almejada por Hamilton e seus contemporâneos $^{8}$. Lieber exerceu grande influência no processo de institucionalização da ciência política estadunidense. É possível afirmar que com ele a "ciência da política" que havia sido desenhada de modo prático pela "citizen literature" encontrou a filosofia política alemã, com seus cânones de pesquisa e seu pesado estilo. Mas esse não foi senão o primeiro encontro que Lieber promoveu. 0 segundo encontro foi com a história. A nascente Staatswissenschaft alemã entrou em território americano primeiramente pela sua mão e, depois dele, pelo grande afluxo de jovens que foram à Alemanha completar seus estudos, principalmente a partir da segunda metade do século XIX. Embora altamente formalizada e fortemente vinculada ao estudo das instituições legais essa Staatswissenschaft enfatizava a história comparada das instituições jurídico-políticas ${ }^{9}$.

De certo modo, Lieber sintetizou nos Estados Unidos o programa de pesquisa desenhado por seu amigo, o professor da universidade alemã de Heildelberg, Johhan Kaspar Bluntschli. Em sua obra Lehre vom modernen Staat, publicada na década de 1870, Bluntschli definiu a Staatswissenschaft como "the science concerned with the State, which endeavours to understand and compreehend the State in its conditions (Grundlagen), in its essential nature (Wesen), its various forms or manifestations (Erscheinungsformen), its development."

\footnotetext{
${ }^{8}$ Francis Lieber aproximou-se, também do futuro desta ciência em um notável apêndice que compôs a terceira edição da obra, preparada por Theodore D. Woolsey, ele próprio cientista político e presidente da Yale University. Nesse texto, dedicado à análise eleitoral e intitulado "A paper on elections, election statistics, and general votes of yes or no", Lieber apresentou uma série de afirmações estabelecendo correlações entre a extensão do sufrágio, o número de votos qualificados, o assunto em votação e a abstenção eleitoral (ver, principalmente idem, p. 419-420). Se a forma de apresentar essas afirmações e o tipo de discurso que as sustenta certamente difere muito dos atuais estudos eleitorais, as preocupações apresentadas pelo autor guardam grande afinidade.

9 Lieber afirmava em seu discurso de posse pretender levar a cabo ao longo de seu curso "a historical survey of all governments and systems of law, Asiatic or European; a survey of all political literature as represented by its prominent authors" (1859, p. 102).
} 
(BLUNTSCHLI, 1892, p.2). Rejeitando o método abstrato-ideológico e o mero empirismo, Bluntschli considerava necessário estudar o Estado a partir de dois métodos: o filosófico e o histórico. Enquanto o primeiro permitiria unir ideias e fatos mediante o pensamento concreto, o segundo possibilitaria reconhecer, explicar e interpretar a conexão interna existente entre o passado e o presente, "the organic devolopment of national life and the moral Idea as revealed in its history" (Idem, p. 7).

O encontro da Staatswissenschaft com a tradição política estadunidense é notável. Até então, a palavra Estado ocupava uma posição secundária no discurso político desse país, comparecendo quase exclusivamente para designar as unidades que compunham a União (cf. GUNNELL, 1993, p. 22). Como visto, desde os Federalistas, e mesmo antes deles, a ideia de uma ciência política, ou ciência da política, ou mesmo ciência do governo era bastante comum. Mas não ocorreu a esses autores utilizar a expressão "ciência do Estado". É, entretanto, exagerado afirmar, como faz Crick (1960, p. 96 e 99), que a ideia e Estado é completamente estranha à experiência e às instituições estadunidenses e só existiu como uma importação ${ }^{10}$.

A influência de Lieber pode ser claramente apreciada na importante obra de Theodor D. Woolsey sobre o Estado, para quem: "On the whole, state is the only scientific term proper for a treatise on politics" (1889, v. 1, p. 142). Presidente do Yale College entre 1846 e 1871, Woolsey seguiu os cânones da Staatswissenschaft de modo ainda mais estrito que Lieber dividindo sua obra em três partes "Doctrine of Rights as the Foundation of a Just State", "Theory of the State" e "Practical Politics" - correspondendo às tradicionais divisões entre Naturrecht, Staatslehre e Politik.

Também Woolsey mostrava temor perante as mudanças na política estadunidense e, particularmente, diante da difusão das idéias da "extreme democracy" as quais favoreceriam "bribery, ballot-stuffing, intimidation of electors, violence at the polls, a general lowering of the character of candidates for public places, the caucus-system, and neglect, on the part of many, of their political duties" (WOOLSEY, 1889, v. 2, p. 141-142). E mais perigosas ainda eram para este autor as modernas teorias do comunismo, as quais "will infallibly lead to intestine war, and has a plausible side, its obvious leadings are calculated to produce greater distrust of democratic principles than all other parts of extreme democracy" (idem, p. 142).

10 Farr (1993) critica de modo consistente essa tese demonstrando a existência de uma "linguagem do Estado" no pensamento político estadunidense muito antes da Guerra Civil. Gunnell, por sua vez, parece aproximar-se de Crick a esse respeito, embora de modo não tão enfático, e afirma que "Lieber had brought the subject matter of the 'state' to the United States" (GUNNELL, 1995, p. 21 e 1993, p. 22). 
Dentre as principais contribuições de Lieber e Woolsey para a ciência política estadunidense estava a crítica das teorias contratualistas do Estado e a definição deste como uma instituição que tinha por propósito a proteção de toda a comunidade (cf. MERRIAM, 1920, p. 316). Distanciavam-se, assim, do pensamento político do final do século XVIII e antecipavam, com base na Staatswissenschaft alemã, uma definição do Estado que seria extremamente influente na Progressive Era e partilhada, embora com ressalvas, posteriormente por expoentes da ciência política estadunidense como John W. Burgess, Woodrow Wilson, William Willoughby e muitos outros. Segundo Charles Edward Merriam,

\begin{abstract}
"Much of the credit for the establishment of this new school belongs to Francis Lieber, a German scientist who came to this country in 1827, and, as an educator and author, left a deep impress on the political thought of America. His Manual of Political Ethics (1838-1839) and Civil Liberty and Self-Government were the first systematic treatises on political science that appeared in the United States, and their influence was widespread" (Idem, 1920, p. 205) ${ }^{11}$.
\end{abstract}

A defesa do liberalismo político e a perspectiva institucional na análise da política características do pensamento maduro de Francis Lieber, bem como sua desconfiança e até mesmo oposição à democracia e ao povo anteciparam traços que podem ser reencontrados na Political Science do final do século XX e início do XXI. A persistência dessas características permite falar de uma duradoura tradição do pensamento político que remonta às "vitoriosas ideias dos Federalistas e sua Constituição de 1787" (SEIDELMAN e HARPHAM, 1985, p. 4). Tais ideias marcaram profundamente a ciência política estadunidense e sua própria institucionalização, muito embora os interesses práticos da geração que sucedeu Lieber tenham sido distintos.

A industrialização, urbanização e modernização da sociedade haviam colocado novos problemas referentes à sua organização política. As sucessivas ondas de imigrantes haviam alterado profundamente a composição demográfica e a cultura política do país. Um amplo movimento autodenominado progressista propôs a reforma das instituições políticas e sociais do país: a reforma do serviço público, a eleição direta para os senadores e o sufrágio feminino. Surgiu, também, um novo tipo de literatura que influenciou enormemente a ciência política da época, o

${ }^{11}$ Sobre as diferenças ver, por exemplo Burgess (1890, v. 1, p. 70). 
jornalismo investigativo dos muckrakers, com suas denúncias da corrupção e do poder das corporações ${ }^{12}$.

\title{
Política e história
}

A consolidação da ciência política como uma disciplina acadêmica nos Estados Unidos teve lugar em meio às profundas mudanças na educação superior desse país. A criação da Johns Hopkins University, em 1876 pode ser considerada um marco dessas transformações. A nova universidade foi concebida como um centro de estudos de pós-graduação e simbolizava o novo espírito acadêmico que começava a difundir-se no país, influenciado pelo modelo das universidades alemãs, a começar pela explícita defesa da liberdade acadêmica feita pelo seu presidente Daniel Gilman em seu discurso inaugural ${ }^{13}$. Cinco departamentos foram criados na nova universidade, um deles intitulado por Gilman de Modern Humanities, no qual predominavam os temas da ciência política:

\begin{abstract}
"More particularly still I refer to the principles of good government, including jurisprudence on the one hand, and political economy on the other. Legislation, taxation, finance, crime, pauperism, municipal government, morality in public and private affairs, are among the special topics. The civil law, international law, the early history of institutions, in short, the history of civilization and the requirements of a modern State come under this department" (1876, p. 44).
\end{abstract}

Foi nessa universidade que se projetou Herbert Baxter Adams, doutor pela universidade alemã de Heidelberg e indicado por Bluntschli, seu orientador, para um posto de Fellowship em História na Johns Hopkins University. Em 1882, começou a trabalhar na série Johns Hopkins Studies in Historical and Political Science, da qual publicou mais de 40 volumes, e logo após recebeu o posto de professor de História e Ciência Política da Universidade. Adams reconhecia-se a si próprio e era reconhecido como historiador e cientista político, e seu trabalho mostrava a forte conexão entre esses dois campos.

\footnotetext{
12 Sobre a influência do "muckraking journalism" sobre a ciência política da Progressive Era, ver Crick (1960, p. 83-88) e Seidelman e Harpham (1984, cap. 3).

13 Segundo Gilman: "If we would maintain a university, great freedom must be allowed both to teachers and scholars. This involves freedom of methods to be employed by the instructors on the one hand, and on the other, freedom of courses to be selected by the students." (1876, p. 54) Sobre o impacto das transformações do ensino superior estadunidense no processo de institucionalização da ciência política, ver Ricci (1984, cap. 2).
} 
O primeiro volume dos Johns Hopkins Studies in Historical and Political Science estava inteiramente dedicado à história das instituições locais nos Estados Unidos. Adams publicou nesse número um artigo especialmente encaminhado pelo historiador inglês Edward A. Freeman para a série, intitulado "Introduction to American Institutional History", no qual procurava apontar as semelhanças de certas instituições dos Estados Unidos com instituições saxônicas do século XIII. O mesmo Adams escreveu uma apresentação - "Mr. Freemans's visit to Baltimore" -, bem como um ensaio sobre as origens germânicas de instituições municipais da Nova Inglaterra (1883; 1883a). Identificando a cidade (town) como as principais células do corpo político na Nova Inglaterra, Adams procurava descrever "the genesis of the town as an institution." Para esse historiador e cientista político, "The town and village life of New England is as truly the reproduction of Old English types as those again are reproductions of the village community system of the ancient Germans" (1883a, p. 8).

As pesquisas de Adams influenciaram uma geração de pesquisadores na Johns Hopkins que produziu um impressionante número de trabalhos publicados sobre a história institucional ${ }^{14}$. Mais do qualquer outro de sua geração procurou fundir história e ciência política partindo da ideia de que "contemporary Politics is only History in the making" (1883, p. 12). Essa ideia era profundamente influenciada pelo pensamento de Freeman, o qual afirmava que "history is simple past politics and that politics are simply present history" (apud ADAMS, 1883, p. 12), lema inscrito no frontispício dos Johns Hopkins Studies in Historical and Political Science bem como na parede do Historical Seminar na Johns Hopkins no qual trabalhava Adams.

A ideia de que a história era simplesmente política passada havia sido reelaborada por Adams e não poderia ser resumida a uma simples reprodução das ideias de Freeman. Essa idea não poderia implicar que toda história pudesse ser reduzida à história política: "While politics and laws are the foundation of the upper strata of history, and while history itself is the deep and eternal substratum of politics, it is well to remember that there are some things in the world which are neither politics nor history" (ADAMS, 1895, p. 70). O editor dos Johns Hopkins Studies estava empenhado, também, em evitar uma concepção reducionista no próprio âmbito da pesquisa sobre as instituições políticas. Para Adams, a ideia grega de que o homem é um animal político, "of man existing in an organized community or commonwealth" era essencial para uma concepção apropriada da história (idem, p. 71). Interpretando Aristóteles à maneira de Tomas de Aquino, o professor de História e Ciência Política estabelecia uma identidade entre o homem

\footnotetext{
14 Ver a bibliografia completa em VVAA (1902).
} 
no Estado e o homem como animal social. Desse modo, estendia o escopo da pesquisa sobre as instituições para âmbitos que tradicionalmente haviam ficado à margem da ciência política. Sua ênfase na propriedade comunal no estudo das instituições municipais da Nova Inglaterra e a importância desta para compreender a soberania da cidade pode ilustrar essa amplitude (cf. 1983a).

As conexões entre história e política, passado e presente, local e mundial sobre as quais Adams insistia frequentemente implicavam em uma perspectiva metodológica baseada nos estudos comparativos. O programa metodológico dos Johns Hopkins Studies in Historical and Political Science era, sem lugar a dúvidas, um programa de pesquisa em história comparada das instituições políticas. Um programa que seu mentor acreditava científico. A influência das pesquisas do alemão Barthold Georg Niebuhr era um ponto em comum entre Adams e Francis Lieber $^{15}$. Metodologicamente, Adams amparava-se em uma leitura das ideias de Leopold von Ranke, segundo a qual o historiador "truly scientific" deveria ter como princípio "to tell things exactly as they occurred", atendo-se estritamente aos fatos em questão, afastando-se das tentativas de generalização e renunciando a toda filosofia (ADAMS, 1895, p. 77. Cf. tb. IGGERS, 1962, p. 21$)^{16}$.

Na Columbia University, John W. Burgess ocupou uma posição semelhante à de Adams. Burgess foi o fundador da School of Political Science dessa universidade em 1880, a primeira instituição acadêmica voltada para o ensino da ciência política. Seu trabalho seguiu durante as décadas seguintes uma trilha paralela àquela preconizada por Adams, adotando, assim como este, um método histórico e comparativo. Logo no prefácio de sua obra mais importante, Political Science and Comparative Constitutional Law, Burgess afirmou: "If, however, my book has any peculiarity, it is its method. It is a comparative study. It is an attempt to apply the method, which has been found so productive in the domain of Natural Science, to Political Science and Jurisprudence" (1890, v. I, p. vi).

Embora não estivesse disposto a separar a história da ciência política, Burgess não se mostrou afeito a confundir ambas ou a afirmar a identidade entre seus objetos. Estava, assim, muito longe de escrever que a história era política pretérita, como Freeman e Adams. Em primeiro lugar porque a ciência política teria assumido, segundo afirmava, o caráter de "science of the national country state" confundindo-se, em seu discurso, com o estudo do presente Estado, assim como o

\footnotetext{
${ }^{15}$ Adams considerava Niebuhr "the real founder of the modern science of institutional history" (1895, p. 75). Lieber, que havia sido discípulo Niebuhr, representava para Adams, "the first beginnings of the historico-political school in American colleges and universities" (idem, p. 79).

${ }^{16}$ Cunningham (1976 e 1981) questionou a decisiva influência de Ranke sobre a historiografia de Adams e procurou afirmar que este possuía uma concepção da História menos positivista do que a afirmada pelos seus críticos. O fato de Adams abrir as portas para uma Kulturgeschichte (argumento central de Cunningham) não diminui, entretanto, a influência de Ranke.
} 
"modern constituional law" confundia-se com as provisões legais do moderno estado liberal (BURGESS, 1897, p. 404). Desse modo, aquela parte da história passada e presente da qual o moderno Estado nacional não fizesse parte seria estranha à ciência política. Em segundo lugar porque a ciência política consistiria em algo mais do que a enumeração de fatos históricos e a identificação de relações causais, abrangendo, também, um elemento de especulação filosófica. Assim, de modo enfático concluiu em seu trabalho apresentado na American Historical Association:

\begin{abstract}
"while there are parts of history which are not political science, and while there is an element in political science which is not strictly history, yet the two spheres so lap over another and interpenetrate each other that they cannot be distinctly separated. Political science must be studied historically and history must be studied politically in order to a correct comprehension of either. Separate then, and the one becomes a cripple, if not a corpse, the other a will-o'-the-wisp" (BURGESS, 1897, p. 408).
\end{abstract}

Adams e Burgess partilhavam um genérico método histórico comparativo, mas diferenciavam-se, fortemente em seus objetos de pesquisa. Ao contrário de Adams, que privilegiava o estudo das instituições locais, a visão de Burgess era fortemente estadocêntrica e sua abordagem institucionalista destacava de modo mais nítido as instituições nacionais estatais strictu sensu. Segundo Burgess, "the political scientist is looking for the state made objective in institutions and laws, and this is the product of history" (1890, v. 1, p. 63. Grifos meus).

Politicamente, Burgess era um liberal-conservador inspirado em uma concepção social-darwinista que considerava a habilidade política uma característica racial inata das nações teutônicas, e estimava as instituições dos Estados Unidos vários estágios à frente das congêneres na linha evolutiva do progresso e uma solução para o problema da ordem e da liberdade (1890, v. 2, p. $40)^{17}$. Ao contrário de muitos dos cientistas políticos da época e de vários de seus alunos, opunha-se decididamente ao movimento de reformas sociais e políticas característico da Progressive Era.

17 A definição de Burgess como conservador é de Bernard Crick (1960, p. 27. Cf. tb. p. $97 \cdot 98$ e SEIDELMAN e HARPHAM, 1985, p. 25). Sobre as qualidades políticas das três grandes nações teutônicas (Alemanha, Inglaterra e Estados Unidos), ver Burgess (1904). 
Para o professor de Columbia, a $16^{\circ}$ emenda à Constituição dos Estados Unidos, a qual dava maiores poderes ao Congresso dos Estados Unidos para criar impostos sobre a renda, havia colocado "all property and all human effort at the mercy of the governmental body which may lay such a tax" (BURGESS, 1915, p. $369)^{18}$. Por meio dessa emenda o governo constitucional desse país havia sido subvertido e deixado de existir: "In fact, since the adoption of the Sixteenth Amendment we have no real constitutional government upon that most important of all subjects, the relation of Government to the Individual's right to property" (idem, p. 370).

Contrariando o que afirmava ser "the prejudice of the masses" e até mesmo as opiniões de pessoas "better educated", Burgess definia as corporações econômicas privadas: "From the point of view of political science, a group of human being, usually belonging to the best class of citizens, associated for the prosecution of a some great enterprise and endowed with certain privileges and obligations" (1889, p. 201). Obviamente essa definição servia para qualquer associação e não apenas para as corporações privadas, mas a função que Burgess atribuía a estas era superior: elas seriam as mais efetivas para prevenir que o governo assumisse a soberania e caísse no despotismo (idem, p. 203). Rejeitando o programa dos chamados populistas, o professor de Columbia afirmava que a destruição das corporações "either directly or indirectly, would lead to a catastrophe in liberty and government which federal republicanism would hardly survive" (Idem, p. 212).

Burgess rejeitou não apenas as reformas econômicas que tinham lugar como, também, as propostas de reforma política com vistas a aumentar a influência do povo sobre o governo, como a regulamentação de referendos ou o recall de governantes e mandatários. Para ele o princípio da soberania popular não deveria ser confundido com a ideia de que o povo, como soberano, realmente deveria governar. A ideia de influência também não deveria ser confundida com a de controle. Burgess destilava contra a ideia do controle popular todo seu preconceito:

"What will generally, if not always, happen is that it will not be the sovereign people, that is, the whole people in sovereign organization, which will control the activities of Government, but that it will be a certain part of the people, not that part which is occupied with private business, with making a living and something more with which to pay taxes, but that part which is loafing about the public buildings, liquor saloons, and gambling-houses, waiting for something to turn up

18 O texto dessa emenda é o seguinte: "The Congress shall have power to lay and collect taxes on incomes, from whatever source derived, without apportionment among the several States, and without regard to any census or enumeration". 
whereby a job, a rake-off, a concession, or a divide of some kind may be had; in other words, it will be 'the mob of the Forum,' that part which one day plunges society into anarchy and the next day is shouting hurrahs for Caesar" (1915, p. 374-375).

Se Burgess encarnava o liberal-conservador, Woodrow Wilson era a quintessência do liberal-reformista empenhado em produzir as mudanças institucionais necessárias aos Estados Unidos sem incorrer em distúrbios radicais (SEIDELMAN e HARPHAM, 1984, p. 40). Wilson, futuro presidente da American Political Science Association (1909-1910) e $28^{\circ}$ presidente dos Estados Unidos (1913-1921) havia sido aluno de Herbert Baxter Adams e treinado, como era comum na Johns Hopkins University, no método histórico e comparativo de pesquisa. Recomendava esse "historical, comparative method" (1887, p. 219) para o estudo da administração estatal e em The State, defendeu esse método, afirmando que: "By the use of a thorough comparative and historical method, moreover, a general clarification of views may be obtained" (WILSON, 1890, p. XXXV).

Assim como Adams, Wilson identificava o estudo científico com a exaustiva compilação de informações a partir dos textos clássicos ou de comentadores destes. Em sua extensa obra sobre o Estado, o futuro presidente dos Estados Unidos reconheceu candidamente ter baseado sua exposição dos modernos governos no Handbuch des Oeffentlichen Rechts der Gegenwart editado por Heinrich Marquardsen da Universidade de Erlangen. Segundo Wilson: "In most cases it embodied the latest authoritative expositions of my subjects accessible to me, and I have used it constantly in my preparation of this work" (1890, p. XXXVI).

$\mathrm{Na}$ Johns Hopkins University, Wilson obteve seu título de Doutor com uma tese de grande sucesso, intitulada Congressional government. Seu estudo sobre o Congresso dos Estados Unidos já era um sinal dos novos tempos na ciência política dos Estados Unidos e ecoava nitidamente os movimentos de reforma social e política da época. O próprio Wilson encontrava-se comprometido com muitos dos ideais da Progressive Era e procurava ardentemente uma saída que permitisse superar os graves problemas sociais evidenciados pela depressão das décadas de 1870 e 1880 e o surgimento de movimentos de contestação política e social.

Seu estudo em Congressional government diferia de muitos de seus predecessores porque assumia a análise das instituições políticas de um ponto de vista dinâmico. O Legislativo dos Estados Unidos e sua relação com os poderes Executivo e Judiciário era analisado em seu funcionamento e não a partir de sua forma jurídica e constitucional. Segundo Wilson, o Congresso caracterizava-se pela fragmentação em compartimentos estreitos e isolados característica da própria pulverização de interesses na sociedade. Essa fragmentação se tornava mais 
evidente no sistema de comitês, o qual implicava na concentração de poder nas mãos de alguns poucos membros do Congresso que por meio de privilégios de iniciativa legislativa e controle exerciam o verdadeiro governo (WILSON, 1900, p. $44)^{19}$.

O estudo do futuro presidente revelou que o Congresso controlava de fato o Executivo e o Judiciário e que ele próprio era controlado por uns poucos membros que ocupavam postos chaves nos comitês: "Congressional government is Committee government" (1900, p. XVI). Era por meio desses comitês que a corrupção tinha lugar. Aliando-se ao muckraking journalism, Wilson denunciava:

\begin{abstract}
"The voter, moreover, feels that his want of confidence in Congress is justified by what he hears of the power of corrupt lobbyists to turn legislation to their own uses. He hears of enormous subsidies begged and obtained; of pensions procured on commission by professional pension solicitors; of appropriations made in the interest of dishonest contractors; and he is not altogether unwarranted in the conclusion that these are evils inherent in the very nature of Congress, for there can be no doubt that the power of the lobbyist consists in great part, if not altogether, in the facility afforded him by the Committee system"
\end{abstract} (1900, p. 189).

Centralizado em comitês controlados por interesses particularistas e particulares o poder do Congresso se mostrava incapaz de resolver os grandes problemas que a nação fazia frente. Mas a defesa que Wilson levava a cabo de um maior controle do Congresso pela opinião publica não implicava em uma defesa do controle popular e democrático das instituições. Em Congressional government, Wilson deixou claro sua ambivalente relação com a democracia e sua profunda desconfiança do princípio da soberania popular (cf. BALL, 1995, p. 44-47). Seu elogio do papel do Senado como um limite à democracia era, também, um explícito elogio do pensamento político dos Federalistas. O Senado era, para Wilson "valuable in our democracy in proportion as it is undemocratic". Era esse caráter não-democratico o que tornava o governo dos Estados Unidos seguro: "the Senate saves us often from headlong popular tyranny" (1890, p. 226-227).

\footnotetext{
19 Segundo Wilson, "The leaders of the House are the chairmen of the principal Standing Committees. Indeed, to be exactly accurate, the House has as many leaders as there are subjects of legislation; for there are as many Standing Committees as there are leading classes of legislation, and in the consideration of every topic of business the House is guided by a special leader in the person of the chairman of the Standing Committee, charged with the superintendence of measures of the particular class to which that topic belongs" (WILSON, 1900, p. 44).
} 
Se o Senado era uma garantia, ele não era uma solução para os problemas enfrentados pelo governo dos Estados Unidos. A solução vislumbrada por Wilson consistia em uma pouco democrática combinação de um incremento e centralização do poder político na pessoa do presidente com uma extensão das funções administrativas de um corpo burocrático livre do controle popular. Sua admiração pela organização do governo inglês, com um forte primeiro-ministro, caminhava ao lado de seu entusiasmo com a burocracia alemã:

\begin{abstract}
"As legal executive, his constitutional aspect, the President cannot be thought of alone. He cannot execute laws. Their actual daily execution must be taken care of by the several executive departments and by the now innumerable body of federal officials throughout the country. In respect of the strictly executive duties of his office the President may be said to administer the presidency in conjunction with the members of his cabinet, like the chairman of a commission. He is even of necessity much less active in the actual carrying out of the law than are his colleagues and advisers. It is therefore becoming more and more true, as the business of the government becomes more and more complex and extended, that the President is becoming more and more a political and less and less an executive officer. His executive powers are in commission, while his political powers more and more centre and accumulate upon him and are in their very nature personal and inalienable" (1961, p. 66-67).
\end{abstract}

Essa alternativa política expunha a própria contradição do pensamento liberal-reformista que o caracterizava ${ }^{20}$. Para Wilson o controle do Legislativo pela opinião pública não deixava de ser o controle presidencial, uma vez que este encarnava e a vontade do povo. O modelo wilsoniano carregava consigo um forte componente bonapartista. Caberia ao presidente colocar-se acima das instituições democráticas e do povo em nome da democracia e do povo, corrigindo assim os defeitos de uma e os arroubos do outro.

A ampliação bonapartista do poder presidencial completava-se nesse projeto com a autonomia burocrática, uma vez que a administração pública era um campo de atividades referente aos negócios e não à política (1887, p. 210). Segundo o então professor de ciência política: "Administrative questions are not political questions. Although politics set the tasks for administration, it should not be

${ }^{20}$ A respeito dessa contradição ver Seidelman e Harpham (1984, p. 42). 
suffered to manipulate its offices" (Idem). Caberia aos especialistas na gestão estatal tomar as decisões referentes à administração pública. A profissionalização dessa gestão era também uma maneira de despolitizá-la, ou seja, retirá-la do âmbito da soberania popular.

O governo desejado por Wilson estava, desse modo, muito longe de ser democrático. Chama a atenção que em uma obra dedicada a estudar o governo dos Estados Unidos, este prefira defini-lo não como democrático e sim como constitucional: "A constitutional government is one whose powers have been adapted to the interests of its people and to the maintenance of individual liberty" (WILSON, 1961, p. 2). É bastante evidente que essa definição não diz palavra sobre quem detinha o poder soberano, deixando em aberto a questão chave da teoria democrática. Os interesses do povo e a liberdade individual poderiam ser preservados sem que a democracia tivesse lugar, ou melhor, para serem preservados necessitavam impedir a democracia ou submetê-la a controles nãodemocráticos.

\section{Conclusão}

Burgess e Wilson tinham posições diferentes quanto às reformas políticas, econômicas e sociais necessárias; partilhavam, entretanto, uma posição ambivalente quanto à democracia e uma desconfiança para com o povo. Essa semelhança, que pode ser encontrada, também, em Lieber, Wollsey e mesmo em Madison e Hamilton, é importante para elucidar um ponto. Não foram poucas as narrativas históricas da ciência política estadunidense que procuraram destacar o compromisso desta com a democracia (p. ex. BERNDTSON, 1987; RICCI, 1984). Mas se apreendermos a democracia a partir de sua etimologia e daquele sentido imprimido pelos clássicos do pensamento político como o princípio da soberania do povo, veremos que desde seus primórdios a ciência política estadunidense manteve com esse princípio uma relação ambivalente ou mesmo conflitante. Isso pode ser verificado mesmo na obra de um liberal reformista, como Woodrow Wilson. O compromisso deste com o princípio da soberania popular era muito mais ambíguo do que deram a entender, por exemplo, Seidelman e Harpham (1985, p. 40-55).

A adesão de autores como Lieber, Woolsey, Adams, Burgess e Wilson aos princípios do liberalismo - ou seja, à defesa da liberdade do indivíduo - não deve, portanto, ser confundida com uma firme defesa dos princípios da democracia. Essa distinção entre liberalismo e democracia é importante para a compreensão de diversos momentos da ciência política estadunidense, particularmente no contexto posterior à Segunda Guerra Mundial, durante a chamada Guerra Fria (cf. p. ex. 
BALL, 1993 e AMADAE, 2003) ${ }^{21}$. Feita esta distinção tornam-se mais nítidos os traços característicos da tradição do pensamento político estadunidense.

Entre o final do século XVIII e o início do século XX foram assentadas gradativamente as bases para a consolidação de uma tradição nacional de ciência política. Bernard Crick, com outros propósitos, chamou esta de American Science of Politics, mas o nome exato que ela se atribuiu foi outro: Political Science. Ao assumir esse nome deixou claro que não se confundia com outras ciências, como a sociologia e a economia. Estabeleceu, assim, não apenas um domínio próprio como também um modo particular de tratar da política ${ }^{22}$.

Liberalismo, democracia, instituições e ciência foram termos gradativamente redefinidos ao longo do tempo, ganhando novos contornos. No final do século XX passou a prevalecer uma versão mais extremada do liberalismo, na qual a intervenção e os controles sobre o mercado preconizados por muitos na Progressive Era passaram a ser considerados indesejados e opostos à democracia. Paralelamente, a idéia de democracia afastou-se do princípio da soberania popular para significar um conjunto determinado de regras e procedimentos de seleção de governantes. O conceito de instituição, por sua vez, abrangeu não apenas as leis e aparelhos governativos, como incorporou novas dimensões, dentre as quais normas, valores e rotinas solidamente estabelecidas. Por último, os procedimentos científicos deixaram de significar a mera recopilação de descrições presentes na literatura existente para abranger um conjunto de sofisticadas técnicas de coleta e manipulação de dados.

As transformações desse léxico político foram, também, mudanças da ciência política. A identificação desta com uma ciência do Estado perdeu força e em alguns momentos, simplesmente deixou de existir. Também o forte vínculo com a disciplina da história foi afrouxado já nas primeiras décadas do século XX. A chamada revolução behaviorarista que teve lugar a partir da década de 1940 definiu claramente essas novas tendências, recusando tanto a ideia de Estado como a de história.

As interpretações estritamente teleológicas do pensamento político que identificam nos primeiros passos da nova República o prenuncio daquilo que viria são incapazes de identificar as transformações desse léxico e os novos significados atribuídos a suas palavras-chave. Mas essas transformações não anulam a existência de uma tradição do pensamento político estadunidense. Entre aqueles velhos significados que as expressões liberalismo, democracia, institucionalismo e ciência adquiriam e os novos que elas assumiram é possível estabelecer mínimos

\footnotetext{
21 Sobre as diferentes interpretações a respeito da relação entre democracia e ciência política nos Estados Unidos, ver Feres Jr. (2000).

22 Tentativas de definir esse domínio ainda no século XIX podem ser vistas nos artigos de Ward (1884), Smith (1886) e Rowe (1897).
} 
denominadores comuns. Na continuidade desse léxico percebe-se a renovada persistência de um compromisso político e uma impostação teórico-metodológica que caracteriza nacionalmente essa ciência.

A hegemonia internacional da ciência política estadunidense fez com que essas características nacionais fossem consideradas atributos da própria ciência política. Esta seria uma ciência das instituições políticas comprometida com a consolidação das ideias e formas políticas liberais. É necessária uma boa dose de paroquialismo para afirmar que a ciência política é uma ciência exclusivamente estadunidense. A própria influência da Staatswissenschaft alemã em Columbia e na Johns Hopkins Univesity já deveria servir para alertar a respeito da diversidade nacional. As razões que levaram ao declínio de diferentes versões nacionais da ciência política, entretanto ainda estão para ser estudadas de modo detalhado. Mas essas razões, certamente, não serão exclusivamente nacionais, exigindo uma história comparada da circulação das ideias políticas.

A história da ciência política estadunidense no século XIX poderia ajudar a esclarecer, justamente, um importante capítulo desse processo de construção de uma hegemonia disciplinar. Mas para tal é preciso deixar os mitos de lado. Longe de ter sido sempre uma aliada da democracia e do povo a ciência política nasceu em oposição a ambos, ou pelo menos alimentando uma profunda desconfiança neles. Terá sido essa sinistra característica relegada ao passado?

\section{Referências bibliográficas}

ADAMS, C. K. Washington and the Higher Education. Ithaca: Andrus \& Church, 1888.

ADAMS, H. B. Thomas Jefferson and the University of Virginia. Washington: Government Printing Office, 1888.

. Is History Past Politics? Johns Hopkins University Studies in Historical and Political Science, v. XIII, p. 67-81, 1895.

. Mr. Freeman visit to Baltimore. Johns Hopkins University Studies in Historical and Political Science, v. I, p. 5-12, 1883.

. The Germanic origin of New England towns. Johns Hopkins University Studies in Historical and Political Science, v. I(II), p. 5-38,1883a.

ADAMS, J. The Works of John Adams, Second President of the United States: with a Life of the Author, Notes and Illustrations, by his Grandson Charles Francis Adams.

Boston: Little, Brown and Co., 1856, 10v. 
AMADAE, S. M. Rationalizing Capitalist Democracy: The cold war: Origins of rational choice liberalism. Chicago: University of Chicago Press: 2003.

BALL, T. American Political Science in Its Postwar Political Context. FARR, J. e SEIDELMAN, R. (Eds.). Discipline and History: Political Science in the United States. Ann Arbor: University of Michigan, 1993, p. 207-221.

. An Ambivalent Alliance: Political Science and American Democracy. FARR, J; DRYZEK, J. S; e LEONARD, S. T. (Eds.). Political Science in History: Research programs and Political Traditions. Cambridge: Cambridge university press, 1995, p.41-65.

BENTLEY, A. F. The process of government: a study of social pressures. Chicago: University of Chicago, 1908.

BERNDTSON, E. The Rise and Fall of American Political Science: Personalities, Quotations, Speculations. International Political Science Review, v. 8, n. 1, p. 85-100, 1987.

BLUNTSCHLI, J. K. The Theory of the State. 2ed. Oxford: Clarendon, 1892.

BRYSON, G. The Emergence of the Social Sciences from Moral Philosophy. International Journal of Ethics, v. 42, n. 3, p. 304-323, 1932.

BURGESS, J. W. Germany, Great Britain and the United States. Political Science Quarterly, v. 19, n. 1, p. 1-19, 1904.

. Political Science and Comparative Constitutional Law. Nova York: Baker and Taylor, 1890, 2v.

. Political Science and History. The American Historical Review, v. 2, n. 3, p.401-408, 1897.

. Private Corporations from the Point of View of Political Science. Political Science Quarterly, v. 13, n. 2, p. 201-212, 1898.

Sons, 1915.

The Reconciliation of Government with Liberty. New York: Charles Scribner's

CASTEL, A. The Founding Fathers and the Vision of a National University. History of Education Quarterly, v. 4, n. 4, p. 280-302, Dec., 1964.

CRICK, B. The American science of politics: its origins and conditions. Berkeley: University of California, 1960. 
CUNNINGHAM, R. J. Is History Past Politics? Herbert Baxter Adams as Precursor of the "New History". The History Teacher, v. 9, n. 2, p. 244-257, 1976.

. The German Historical World of Herbert Baxter Adams: 1874-1876. The Journal of American History, v. 68, n. 2, p. 261-275, 1981.

ELLIS, R. J. Radical Lockeanism in American Political Culture. The Western Political Quarterly, v. 45, n. 4, p. 825-849, Dec. 1992.

FARR, J. Political Science and the State. FARR, J. e SEIDELMAN, R. (Eds.). Discipline and History: Political Science in the United States. Ann Arbor: University of Michigan, 1993, p. 63-79.

FERES JR, J. Aprendendo com os erros dos outros: o que a história da ciência política americana tem para nos contar. Revista de Sociologia e Política, n. 15, p. 97. 110, 2000.

GILMAN, D. C. Addresses at the inauguration of Daniel C. Gilman, as President of the Johns Hopkins University. Baltimore: John Murphy \& Co, 1876.

GOODNOW. F. J. The Work of The American Political Science Association. Proceedings of the American Political Science Association (First Annual Meeting), v. 1, p. 35-46, 1904.

GUNNELL, J. G. The descent if Political Theory: the genealogy of an American vocation. Chicago: University of Chicago, 1993.

. The declination of the "State" and the Origins of American Pluralism. FARR, J; DRYZEK, J. S. e LEONARD, S. T. (Eds.). Political Science in History: Research programs and Political Traditions. Cambridge: Cambridge university press, 1995, p. 19.40.

HAMILTON, A. The Works of Alexander Hamilton: ed. Henry Cabot Lodge (Federal Edition). New York: G.P. Putnam's Sons, 1904, 12v.

IGGERS, G. G. The Image of Ranke in American and German Historical Thought. History and Theory, v. 2, n. 1, p. 17-40, 1962.

JEFFERSON, T. The Works of Thomas Jefferson, Federal Edition. New York, London: G.P. Putnam's Sons, 1904-1905, 12 v.

LIEBER, F. Inaugural Address of Francis Lieber, LL. D. Professor of Histpry and Political Science. In: VVAA. Addresses of the newly-appointed professors of Columbia College with an introductory address by William Betts, LL. D. Nova York: By Authority of the Trustees, 1858, p. 55-116. 
. The ancient and the modern teacher of politics: and introductory discourse to a course of lectures on the state. Nova York: The Board of Trustees, 1860.

. On Civil liberty and self-government. Filadélfia/Londres: J. B. Lippincott \& Co./ Trubner \& Co., 1874.

. Manual of Political Ethics: designed chefly for the use of Colleges and students of Law. 2 ed. Filadelfia/Londres: J.B. Lippincott/Trübner, 1876, 2v.

MACHIAVELLI, N. Tutte le opere. Florença: Sansoni, 1971.

MADISON, J. The Writings of James Madison, comprising his Public Papers and his Private Correspondence, including his numerous letters and documents now for the first time printed: ed. Gaillard Hunt. New York: G.P. Putnam's Sons, 1900, 9v.

. et al. The Federalist (The Gideon Edition): edited with an Introduction, Reader's Guide, Constitutional Cross-reference, Index, and Glossary by George W. Carey and James McClellan. Indianapolis: Liberty Fund, 2001.

MERRIAM, C. E. A History of American Political Theories. Nova York: Macmillan, 1920.

. The American Party System: an Introduction to the Study of Political Parties in the United States. Nova York: Macmillan, 1922.

NCES (NATIONAL CENTER FOR EDUCATION STATISTICS). Digest of Education Statitics, 2007. Disponível em: <http://nces.ed.gov/programs/digest/d07/>. Acesso em: [21 jan. 2008].

PERRY, B. The American spirit in literature. New Haven: Yale University, 1918.

PETERS, G. B. El nuevo institucionalismo: teoria institucional en ciencia política. Barcelona: Gedisa, 2003.

RICCI, D. M. The tragedy of Political Science: politics, scholarship, and democracy. New Haven: Yale University, 1984.

ROSS, D. The origins of American Social Science. Cambridge: Cambridge University, 1991.

ROWE, L. S. The Problems of Political Science. Annals of the American Academy of Political and Social Science, v. 10, p. 17-38, 1897.

RUSH, B. The selected writings of Benjamin Rush: edited by Dagobert D. Runes. Nova York: The Philosophical Library, 1947. 
SEIDELMAN, R. e HARPHAM, E. J. Disenchanted realist: Political Science and the American crisis, 1884-1984. Albany: State University of New York, 1985.

SMITH, M. Introduction: The Domain of Political Science. Political Science Quarterly, v. 1 , n. 1 , p. $1 \cdot 8,1886$.

VINCENT, J. M. Herbert B. Adams: a biographical sketch. VVAA. Herbert B. Adams tributes of friends: with a bibliography of the Department of History, Politics and Economics of the Johns Hopkins University, 1876-1901. Baltimore: The Johns Hopkins Press, 1902, p. 9-23.

VVAA. Herbert B. Adams tributes of friends: with a bibliography of the Department of History, Politics and Economics of the Johns Hopkins University, 1876-1901. Baltimore: The Johns Hopkins Press, 1902.

WARD, L. F. The Claims of Political Science. Science, v. 3, n. 72, p. 748, 1884.

WASHINGTON, G. George Washington: a collection, compiled and edited by W.B. Allen. Indianapolis: Liberty Fund, 1988.

WILSON, J. Collected Works of James Wilson: edited by Kermit L. Hall and Mark David Hall. Indianapolis: Liberty Fund, 2007, 2v.

WILSON, W. Congressional government: a study in American politics. Boston e Nova York: Houqhton Mifflin Co., 1900.

. The State. Elements of Historical and Practical Politics: A Sketch of Institutional History and Administration. Boston: D. C. Heath \& Co., 1890. 222, 1887. The Study of Administration. Political Science Quarterly, v. 2, n. 2, p. 197. 1961. . Constitutional Government in the United States. New York: Columbia University,

WOOLSEY, T. D. Political Science: The State Theoretically and Practically Considered. 2 ed. Nova York: Charles Scribner's Sons, 1889, 2v.

Álvaro Bianchi - albianchi@terra.com.br

Recebido para publicação em novembro de 2010. Aprovado para publicação em maio de 2011. 